\title{
To Decide or Not to Decide. Recognition, Intersubjectivity, and the (Un)expected Role of Unexpectedness
}

\author{
Francesco Forlin \\ University of Perugia
}

\begin{abstract}
Recognition is the key to intersubjectivity, as it implies a relation only possible between rational subjects. To recognize means therefore to make a decision, maybe one of the most important decisions, so that a philosophical reflection on intersubjectivity cannot be separated from a reflection on the social and political nature of decision. This leads, to how a simple theory of decision is to be found even in a deeply intersubjective context like the one of role and tabletop games. Aim of this research is to reflect on the role of unexpectedness and unexpected-and thus free-decisions in fields like those described by recognitions, States, and games, bringing into dialogue some thoughts of Hegel, Schelling, and C. Schmitt.
\end{abstract}

Keywords: decision, recognition, intersubjectivity, unexpectedness, game

\section{Introduction: Recognition and Decision}

Within western philosophy, recognition is one of those topics capable of bringing into dialogue both philosophy and culture, in their broader meaning. I think it is here crucial to reflect on what ties recognition, in both its public and social dimension, and the process that takes place in order to make this recognition possible, which is the decision. Are, and eventually how, values and laws committed to each other, namely when it goes on values inspiring laws that are supposed to make recognition possible? And, is it possible to decide on these laws and values just like in the case of any other topic? The very nature of recognition remains indeed quite problematic, and so does the nature of the decision supposed to realize it.

In this talk, I will try to stress three aspects of this topic.

Firstly, I will start from a brief confrontation between Schelling and Hegel regarding how German Idealism thinks the dialectical dimension of recognition.

Secondly, I will dedicate my attention to how decision comes into play when it goes on explaining what really takes place when two individuals face each other, mainly with the help of some lines about Carl Schmitt's theory of decision and its opponents.

Thirdly, I will conclude by providing a sneak peek at how the same topic is to be found in a quite peculiar context of contemporary culture, which is the world of board and role games.

Francesco Forlin, Ph.D., Department of Philosophy, Human, Social, and Education Sciences, University of Perugia, Italy; main research fields: Philosophy of Education, Theory of Intersubjectivity, German Idealism, History of Philosophy, and Game Studies.

This article is the result of a research conducted with the contribution of IHRC, International Human-being Research Center (http://www.stromata.org/centro-ihrc/). 


\section{Recognition and Idealism}

Recognition is the key to every intersubjective kind of relation.

Regardless of what pushes us forward and of what lies in our past, every single act regarding something more than just my personal being has to do with recognition. Recognition is therefore the most important condition required every time I deal with other persons; I could actually state that recognition is required every time I deal with reality, in the broadest meaning. Now, reality itself is a quite complex concept, since it deals with many possible meanings. It is however highly significant that contemporary philosophy tends to give up the challenge regarding the true meaning of reality. The only possible way used by contemporary thought to think reality involves philosophy of language- the focus is not on reality itself but on how we talk about it. The reflection on language has therefore gone very far during the last fifty years, and one of the most important achievements of this research regards the discover of the deeply intersubjective and relational nature of language, which, once again, brings recognition in discussion. This tendency reveals some kind of use of the idealistic insight regarding reality, which is the assumption that reality needs to be reduced to action. Reality is not simply to be understood like some sort of fact, rather than a process, something which is not, so to say, happened once and for all, but something which is always going on, depending on how human beings involved in the process are going to build it. Recognition involves a consensus of the will which calls into play the meaphysical dimension of the Self. Only a human being is capable of saying yes and therefore of giving to his interlocutor the chance of being recognized as a recognizable-and-thus-recognizing being. If we look at this point from a Christian perspective this has at least two meanings. Only someone who has already been recognized is capable of recognizing. Since this could lead to a nearly infinite succession, it can here be observed that the primal and most influencing recognition is the one made possible by Jesus Christ's sacrifice. It is precisely in that moment - the moment which sees Christ literally giving His own human life to His human friends and brothers, in everything similar to Him except for original sin - that a new sort of relation comes into light. This relation is not a mutual relation: It starts—and finishes, on the Cross—as a gift given from Someone who is and has everything to someone who, in comparison, is and has nothing.

Here we face an interesting dilemma. We are figuring the first and most important relation as a relation which ties human consciences to Someone who, due to His divine nature, is supposed to simply remain outside and beyond every possible relation. This is only true unless we start to reflect on the Trinity. According to some developments of Trinitarian ontology—like for instance those present in Piero Coda's thought- the core of Trinity is the revelation of God's nature as relation. Following this path, it is possible to encounter there not only a related God, but a God who truly is the principle of every possible relation. All that the human being has to do, in order to achieve the key to recognition, is to make the decision of accepting God's offer, simply by saying yes to His first move.

It is thus given birth to a new movement, which we could define a dialectical one insofar we look into it from God's perspective: It is precisely this kind of movement what Schelling defines Offenbarung Gottes in his 24th lecture on philosophy of revelation. At the same time, it is for Schelling crucial to underline that, in order to remain a true revelation, every content related has to appear brand new, so that one could not conceive it before the revelation occurred. The problem of recognition is therefore linked to these two plans of research: the first from above-dialectical — and the second from below-more personal, regarding what happens to individuals. The reason isn't capable to grasp the very essence of the former, since it should involve a deep 
understanding of something which, in order to be understood, has to be revealed. Schelling dedicates some pages to stress this point. Only what is at the beginning a posteriori, can later become a priori, which is another way to explain the same concept: God has to make the first step, before the human conscience can become aware of His real nature. What happens between God and man can be used to understand what also happens between human beings, since Schelling assumes that the former sort of relation is condition to the latter.

Now, is then recognition firstly intended to address the human being or to make God's nature clear to God Himself? As it is known, the latter is Hegel's position, made explicit since at least the Phänomenologie des Geistes, where the philosopher devotes himself to explaining how the Absolute, as Geist, is going to find himself through his own lost and discovery. However, in Hegel, we face not the idea of an Absolute which is absolute only at the end: The true movement of the Spirit is indeed a circular one, which means that the ending point is nothing more than the beginning one fully known in its own truth.

That is why the real problem we face when it goes on recognition in Hegelian terms is not, as it is often said, that there is no space for intersubjectivity.

As a matter of fact, as V. Hösle states, intersubjectivity is deeply rooted in Hegel's thought, yet it is condemned to remain a task to be fulfilled, since the philosopher did not provide its foundation. That said, Hösle devotes many pages of his Hegels System to underline how and why intersubjectivity remains the big "to-do" of Hegel's philosophy, mainly considering the deep boundary linking Geist, Anerkennung, and Selbstbewu ßtsein. Regarding our problem, the point is eventually not at the end, but at the begin: What kind of intersubjectivity are we talking about, if we talk about a relation which is present from the very beginning, without any real chance of something new to come to surface? Can intersubjectivity—and true recognition as well—exist without the idea of what we could define unexpectedness?

There is, indeed, a chance. I believe it is linked to Hegel's theological thought, namely regarding what Coda defines, in his Il negativo e la Trinità, Hegelian Denkform by the meanings of its Christian heritage, mainly regarding how crucial become, after the publication of the Grundlinien der Philosophie des Rechts (1821), two particular topics: history and religion. These topics are intensely related: Only the Christian religion conceives history as the stage where the Trinitarian Absolute Spirit reveals its nature through its own dissolution (das Negative). The Trinity thus becomes the pivotal point of every possible understanding of Hegel's intersubjectivity.

I would like to highlight here two points of interest.

(a) In a letter to August Tholuck dated 1826 regarding the presence of Trinitarian ideas in far East religions, Hegel states that he (Hegel) disagrees substantially with his interlocutor, since never he wanted to conceive the Trinity as a speculative construct, yet as something which is intended to develop its truth during history being at the same time beyond history. Finally, he ends the letter by writing that he truly finds appaling the idea of an explication of the Trinity just in the same way we can explain the origin of any other phenomenon. Trinity-and therefore God's nature-is someway supposed to remain not completely explicated, which, again, means somehow unexpected.

(b) In the Vorlesungenüber die Philosophie der Religion (I, 9), Hegel explains that "God's Spirit, in the strictest theological form, is essentially in His community." This means that the Spirit consists of two faces: One is God properly said, the other is the spirit which inhabits the one who knows God. We could summarize by saying that, in Hegel, God Himself consists of the relation between these two aspects, of their own being-related to each other. 
It seems that the only way to preserve the "unexpectedness" of any intersubjective relation involves the problem of God's nature and God's truth.

If we come back to Schelling, we may find that we face here the problem of what Schelling, since the Freiheitsschrift (1809), calls Grund and Existenz, which means the difference between what God considered really actu is (Existenz) and what, in God, is yet capable of, so to speak, "not becoming God.” The Italian philosopher Luigi Pareyson thought that this position leads Schelling to develop a sort of reflection which is not anymore idealistic, but existentialistic. This shows eventually up in at least three points:

(1) God's Grund is built up God's Ur-Grund (primary ground) which eventually has something even more ancient before him, the so-called Un-Grund (a not-ground), so primary that it cannot be thought nor put in connection to anything. That's why thought is not going to play a primary role-like in Hegel.

(2) The true, deep nature of things can only be perceived via intuitions and feelings, since, like it has just been said, thought and reason can only give form to something which has already begun to exist. It is here important to underline that, for Schelling, every sort of existence is to be intended like a birth from the darkness into light. So the darkness comes indeed first.

(3) What comes first is therefore not a rationally-conceived concept, but something which Schelling defines Vermögen des Guten und des Bösen, which is the freedom intended not, like since St. Augustine, as a choice for the good, but as something we could define as the balance that is not yet evil neither good: a moment where one can still decide for one thing and its very opposite. This balance is excluded once a decision is made. Like Heidegger stated in his study on Schelling's Freiheitsschrift, Schelling tries here to cancel Aristotle primacy of energheia (actuality) over dynamis (potentiality) in order to state the primacy of dynamis over energheia, just because with every energheia — a decision—comes along the exclusion of one or more dynamis.

To summarize the first results of our inquiry: Recognition of the Self is possible only thanks to a recognition of the Other, which, in turn, is only possible as consequence of a free decision. This point is deeply investigated by Schelling and Hegel, who add to it the reflection on God's nature as source of every possible relation. The research about human recognition leads therefore to the research about a related God. So the focus goes on the very nature of decision, seen as free insofar unexpected and capable, once made, of giving reality to something not existing before in an unpredictable way. But since only human beings do make decisions, and human beings are necessarily tied, as we have briefly seen, to their intersubjective recognition, we find that to research decision's nature means to reflect on the nature of intersubjective structures.

\section{The Social Nature of Decision}

This leads us to a reflection regarding the social nature of decision, which means regarding consequences and effects of decision on an intersubjective plan.

I would say that the decision in itself has encountered some bad luck, mainly in the second half of 20th century and mainly in Western Europe. Second World War brought with herself fear for both decision and decisionism.

This was particularly true in Germany, where C. Schmitt's theory of decision was judged directly implied with national-socialist ideology, due to the intellectual support Schmitt gave to the Third Reich regime. In truth, Schmitt's theory of decision has a far more deep meaning, since it is one of the most radical and interesting alternatives to liberal thought. For Schmitt, the ruler has the power, in taking the decision, to set aside the positive legal and constitutional order in its entirety and to create a brand new positive legal and constitutional 
order, together with a situation of social normality that fits it. Decision is, at the same time, source and ground of any possible law. It follows that the ruler cannot base his claim to be acting in the name of the people on any kind of formal authorization. And yet, the ruler claims to exercise the constituent power of the people.

What is more, the constitutional order he is to create is to be considered as legitimate since it rests on the people's right to give itself a constitution, based on the clear distinction friend-enemy. The point of this remark is that a state can only be legitimate if its legal boundaries embody a clear friend-enemy distinction. In order to achieve this aim, Schmitt clearly implies that the ruler, acting in the interstices between two periods of positive constitutional order, must homogenize the community by appeal to a clear friend-enemy distinction, as well as through the suppression, elimination, or expulsion of internal enemies who do not endorse that distinction. In so doing, the ruler expresses the community's understanding of what is normal or exceptional and of who belongs, and he creates the homogeneous medium that Schmitt considers to be a precondition of the legitimate applicability of law. Schmitt observes that his concept of the political is not belligerent. It does not glorify war, but merely claims that a community that is interested in living politically needs to be willing to go to war if it perceives its political existence to be threatened.

It is now not possible to deepen the political consequences and meanings of Schmitt's theory. I would only underline that, philosophically speaking, Schmitt goes straight to the point that every decision (from de-caedere, literally cut-off) implies an interruption, something which-morally speaking-we could define as a not-peaceful act, the cutting off of every other not chosen possibility; every decision forces the doer to accept every consequence of his course of action.

Since every decision comes as a possible solution to a problem, and given the fact that it was obviously impossible to simply eliminate problems, it seems to me that European post-war thought tried to figure out how to solve problems without deciding, trying at the same time to re-configure the system of social and communitarian recognition.

Three examples:

(a) By refusing that both subjects and societies can be considered as homogeneous entities linked by a common identity, underlining on the contrary the complexity of mutual relations existing between them. This way of reflection, which is for instance to be found in Alain Caillé's Critique de la raison utilitaire, leads to a profound critic towards neo-liberalism and shows a double sort of relation with Schmitt's theory of decision and society. On one hand, Caillé accepts Schmitt's own position regarding the supremacy of social and cultural factors over economical ones; but on the other hand, he cannot accept Schmitt's idea of identity, which follows from the friend-enemy decision as primary framework of agency for both individuals and groups.

(b) By accepting Schmitt's link between power-decision-law only in order to criticize all of them. This is Michel Foucault's way of thinking. For him, every aspect of social recognition needs to be reinvented, with the aim of going beyond the traditional balance of power which takes place in modern as well as in ancient societies. A decision can here be made only after a long and difficult process of de-construction of every single aspect lying at the ground of every conscious and unconscious human act.

(c) By taking away from decision every possible content and underlining the formal boundaries capable of making a decision a good decision. This is the direction taken from K. A. Apel and J. Habermas with their Diskursethik and Theorie des kommunikativen Handelns. In this case, the fear towards Schmitt's praise of identity and how it could have inspired totalitarianism is made explicit within the context of German post-war reflection. Habermas, in particular, is quite clear stating that contemporary Germany should build its identity 
over the struggle against any kind of "strong" identity. To avoid strong decisions - which in turn are inevitably made possible only by strong doers - and to bound them within a robust net of rules becomes here crucial in order to achieve a sort of society and recognition whose main aspect is to remain strictly formal, and whose main purpose is to grant everybody the broadest kind of openness and acceptation. This remains true, for example, even in M. Bratman and R. Tuomela's social ontology, a part of analytical philosophy devoted to the study of collective consciousness, which is therefore described as a matter of forms and procedures, rather than contents.

Let's try to summarize the results of this second part of the research.

First of all, we used C. Schmitt's theory on decision to highlight how and why every single decision implies an interruption and some sort of a new beginning. By the meanings of this theory, contemporary philosophy-like for instance the one present in the thought of A. Caillé, M. Foucault, and J. Jabermas-tends to avoid decision, linking it to the dangers related to totalitarianism.

The task given to present and future reflection is therefore the re-discovery of decision - in its broader and deeper meaning — as crucial and pivotal point of both individual and intersubjective recognition.

\section{Conclusion: Decision, or the Feeling of Unexpectedness}

I will now try to bring part of these reflections in a world which is normally not observed from a philosophical point of view. The world I am talking about is the world of role play games, both "pen \& paper" dungeons \& dragons style, and tabletop or cards ones. Just like the name suggests, the main feature of this sort of games is not, like in the so-called "german" games, to create a challenge, a competition between players with the aim to reveal who's the one capable of a better management of resources or a better strategy of conquest. Main feature of every role-game is, simply said, to tell a story. There is always a kind of main plot, which can either be narrated and managed by the Game Master or by game cards with narrative texts whose use changes depending on the player's choices. The more the story is "lived" by the players and not simply "gamed," the more they will enjoy it. Clearly enough, we face here some sort of epoché which, in order to fulfill its cathartic purpose, needs to be taken seriously from the persons who participate to the game.

But in this kind of game the real key to success is the quality of human interactions taking place between the players: how they interact, what sort of relations do they create, how do they organize the fictional society which has to face the quests the game gives to them—it is, once again, a matter of recognition. It is well known between players addicted to game-just like me-that every aspect of role-play games has to do with the feeling of freedom, which is, again, the feeling of making decisions, not the feeling of handling resources.

In order to be meaningful, and therefore enjoyable, every single act the player does has to appear as the result of a choice willingly made.

However, it is interesting to note that one of the most discussed and appreciated cards- a card whose name is "Strange Solution" — of a recent role-play card game-Arkham Horror, inspired to the works of the science-horror-fiction U.S. author H. P. Lovecraft—firstly asks to the player to make a particular "skill check" - which consists in rolling a certain number of dices depending on the character skill value - then, if the check was passed, makes the player note in the campaign log that "the solution has been identified" without saying just nothing about what will the consequences of this fact be. Every forum of discussion on internet has literally been invaded - in the last months - with comments of players who found this card absolutely amazing. It seems therefore that the players find highly enjoyable not only to have the power to act freely, but also to act 
so freely that the very purpose and effect of their actions can remain for the moment unknown. To decide means here to accept a double degree of randomness: first the randomness of dice, then the randomness of unknown effect.

It is, in other words, what we have already defined unexpectedness. Decision has much to do with unexpectedness. The key to human recognition and decision is maybe not only yet to be found: It is possible that to find it would lead to destroying it, since its very essence can simply consist in making a decision just to make it, without any reasonable purpose: It is the decision to decide, which, in turn, gives us the chance of being recognized as free human beings.

To decide or not to decide. That is the question.

\section{Works Cited}

Apel, K. O. Dialog als Methode (Dialogue as Method). Göttingen: Vandenhoeck \& Ruprecht, 1972.

Bratman, Michael. Shared Agency. A Planning Theory for Acting Together. New York: Oxford University Press, 2014.

Caillé, Alain. Critique de la raison utilitaire (Critique of Utilitarian Reason). Paris: Éditions La Découverte, 1988.

Coda, Piero. Il negativo e la Trinità. Ipotesisu Hegel (The Negative and the Trinity. Hypothesis on Hegel). Roma: Città Nuova, 1987.

Foucault, Michel. Surveiller et punir. Naissance de la prison (Discipline and Punish: The Birth of Prison). Paris: Gallimard, 1975.

Habermas, Jürgen. Theorie des kommuntikativen Handelns (Theory of Communicative Action). Frankfurt am Mein: Suhrkamp Verlag, 1981.

Hegel, Georg Wilhelm Friedrich. Phänomenologie des Geistes (Phenomenology of Spirit). Bamberg und Würzburg: Goebhardt Verlag, 1807.

---. “Vorlesungenueber die Philosophie der Religion (Lectures on Philosophy of Religion).” Gesammelte Werke. hrsg. von der Nordrhein-Westfälischen Akademie der Wissenschaften und der Künste. Hamburg: Meiner Verlag, 1968.

Hösle, Viktor. Hegels System. Der Idealismus der Subjektivität und das Problem der Intersubjektivität (Hegel’s System. Idealism of Subjectivity and the Problem of Intersubjectivity). Hamburg: Meiner Verlag, 1987.

Pareyson, Luigi. “La filosofia e il problema del male (Philosophy and the Problem of Evil).” Annuario Filosofico 2 (1986).

Schelling, Friedrich Wilhelm Joseph. Philosophische Untersuchungenüberdas Wesen dermenschlichen Freiheitsschrift und die damitzusammenhängenden Gegenstände (Philosophical Inquiries into the Essence of Human Freedom). München, 1809.

---. "Philosophie der Offenbarung (Philosophy of Revelation).” Sämtliche Werke. hrsg. von K.F.A. Schelling, 14 Bde. Stuttgart und Augsburg: Cotta Verlag, 1856-1861.

Schmitt, Carl. Politische Theologie. VierKapitelzur Lehre von der Souveränität (Political Theology. Four Chapters on the Concept of Sovereignty). Berlin: Duncker \& Humblot, 1922.

Tuomela, Raimo. The Philosophy of Sociality: The Shared Point of View. New York: Oxford University Press, 2007. 